\title{
Educational dropout in Israel - general progress in the last decade
}

\author{
Usama HEIBं, Theofild-Andrei LAZĂR
}

\section{Abstract}

In Israel, the awareness on the youth dropout from school problem has increased in the last decade. There is no doubt that dealing with this phenomenon poses a challenge to the Israeli society and to the authorities responsible for educational services. It turns out that certain groups among the Israeli population are at a higher risk of dropping out from school than others. As a result of it, many teenagers from these groups do not complete their high school studies and are unable to integrate in a qualitative and significant manner in the army and the labour market. Moreover, dropping out of the education system may have a significant impact on the mental and economic well-being of young generations of citizens. Therefore, preventing the problem of dropout and helping the youths to get back into the loop is a tremendous challenge to the Israeli education system. Even if in the last decade Israel registered lower rates of educational dropout then before, middle, and high-school students are still struggling with the issue. Therefore, the article underlines theoretical aspects regarding educational dropout as general framework and presents the specifics of the phenomenon in the Israelian educational system. The last part of the paper follows, based on secondary data analysis extracted from national official data, the differences between the two main state educational systems in Israel (Hebrew and Arabic) in terms of tendencies on educational dropout in the last ten school years. The data reveals that, even if there is progress in preventing educational dropout in both systems, the Arabic system registers significantly higher rates that the Hebrew educational system.

Keywords: Educational dropout, youth in risk, educational system, covert and overt dropout.

\section{Introduction}

The problem of dropping out from formal education frameworks is a global phenomenon, that not only concerns the national educational systems, but the whole societal mechanisms, having potential consequences in a variety of important areas: economic development, societal security, wellbeing and so on.

Since education is the wheel that drives individuals to mobility, activity and meaningful participation in the community and state life, the phenomenon of dropout (covert or overt) is actually one of the central variables that continuously feed the social gaps formation in contemporary societies, including Israel.

In Israel, the data shows improvement in the last decade for the general population, but certain at-risk categories continue to register significantly higher rates of dropout compared to the national mean.

•PhD student, Israel, West University of Timișoara, Romania, e-mail: usama.heib10@e-uvt.ro

- Associate Professor, West University of Timișoara, Romania, e-mail: theofild.lazar@e-uvt.ro 
The present paper follows some theoretical aspects about the concept of educational dropout and presents a secondary data analysis of general tendencies on dropout in Israel in the last decade for pupils from middle and high-school, considering these two educational periods as high risk ones. Previous studies show that the risk of youth dropping out in Israel is mainly at the age of 15-17, which is the age at which the student moves from the middle school to the high school system (Moore, 2008).

\section{A theoretical frame for educational dropout}

The current literature has no unequivocal and comprehensive definition of dropout, many researchers referring to this lack of uniformity in defining the phenomenon (Lahav, 2013; Dekkers \& Claassen, 2001). For example, some authors define dropout as leaving the regular school even if the child continues to study in an alternative framework, while others define dropout only as a complete cessation of studies.

The general tendency when defining educational dropout is the focalisation on the physical departure of the child from the education system intended for his or her age group. Nevertheless, in the last decades the literature has increasingly started to emphasize the "hidden dropout" that expresses a process of disengagement among students who are still formally registered but who do not benefit from the learning process. Situations of disengagement are expressed in a high number of absences, low achievements that point to inadequate learning functioning, feelings of alienation toward the school, behavioural and social problems (Lloyd-Jones et al. 2010; Ferguson et al. 2005, Atkinson et al., 2000).

Dropout is a dynamic process, and today it is widely described using two concepts: overt dropout and covert dropout. Overt dropout describes a situation of physical disconnection of the youngsters from the education system. Among them, three distinct groups can be distinguished: (1) youths who have decided to disconnect from the education system and stop looking for educational alternatives; (2) youths who after a short period of time are cut off from the education system and start looking for a way to reintegrate back into the system; (3) All those youths who, because of unfortunate life circumstances and neglect, have remained outside the educational framework.

Covert dropout is represented by the group of youths who do not attend the educational framework frequently and if they do, they remain inactive in the classroom. It is important to note that covert dropout has no uniform and agreed upon definition, but there are signs that may help identify and locate it. The population group that has an increased risk of reaching the covert dropout situation is represented by youngsters who usually miss many schooldays and have a personal file with severe anti-social problems (Cohen-Navot et al., 2012).

The difficulty in accurately estimating the exact rate of youth dropping out of school every year stems from the complexity of the situation and the lack of reporting. A method is used by the Central Bureau of Statistics from Israel, according to which a national sample of the population of all ages is examined for their occupation. The findings of the 
past few years show that the covert dropout encompasses a percentage similar to that of the overt dropout.

Many factors influence dropout. Some are connected to individual characteristics like personality, some are derived from the social environment like the family and the community, and some are derived from the way the education system is constructed and implemented (Cohen Navot et al., 2011).

Many studies point to the characteristics of youth personality as factors that cause dropout. Examples of individual characteristics that can lead to school dropout are: difficulties in self-discipline or postponement of gratification, difficulties in concentration, tendency to aggression, emotional problems and difficulties in coping with stress, low motivation or life crisis periods. The direct effects are low scholastic achievements and accumulation of school failures, difficulty in adaptation, and problematic school behaviour leading in the first phase to covert dropout (KnestingLund, O'Rourke \& Gabriele, 2015; Ben-Rav \& Kahan-Strawczynski, 2011). In the long run it can lead to negative attitudes toward the school, accumulation of school absences, a history of transitions from one school to another, and finally to complete educational dropout.

The family is the framework in which the child's basic experiences are shaped and in which they are equipped with the main resources that enable them to deal with the educational framework and to benefit from it. The literature shows for example that families with low socioeconomic status constitute a catalyst for school dropout (Dupéré et al. 2018). Families with many children, unemployed parents or low-income ones are associated with problems of dropout and low achievement (Ben-Rav \& KahanStrawczynski, 2011). Other family characteristics like a weak father figure, lack of parental support for the child, and also associated with educational dropout (Ben-Rav \& Kahan-Strawczynski, 2011; Englund, Egeland \& Collins 2008).

From the cultural perspective, differences in the norms and expectations of children and youth, who come from different cultural backgrounds than the dominant ones at school, can sometimes lead to many difficulties in coping with school demands, especially among immigrant students; a thing that can lead to dropout (Dupéré et al. 2019).

Factors related to the educational system and schools are very influential towards the dropout phenomenon. Many researchers and educators point out that ineffective teaching methods, poor quality of teaching, low expectations from teachers towards their students performances, lack of funding and resources, and a multitude of irrelevant curricula are significant factors for dropping out (Cabus and De Witte, 2016; KnestingLund, O'Rourke \& Gabriele, 2015; Ferguson et al., 2005).

There is a connection between scholastic achievements and future dropouts. It was found that low scholastic achievements and poor attendance are central characteristics prior to leaving the school. In addition, the students' low self-perception is also a critical feature in predicting dropping out the education framework. According to many researchers, there is a direct and unbreakable relationship between the feeling of social 
alienation and the inability to function normally in school (Cohen-Navot et al., 2012; Cohen-Navot, 2011; Andrei, Teodorescu \& Oancea, 2011).

In addition, studies indicate that adolescents who reported a high sense of alienation in their schools tended to be largely absent from school (covert dropout) and then stopped altogether from going to school (overt dropout). The findings also show that adaptation of the student to the school framework influences the decision of perseverance or dropout. The higher the student's adaptability is, the greater the chances of perseverance and stability within the school. One study argues that the greater the sense of self-efficacy of the teenager, the greater the level of adaptation to the school framework, which is expressed in the student's attitudes and behaviour (Shemesh, 2013). Negative attitudes toward school are among the aspects that characterize covert dropouts. Moreover, another study indicates that when teenagers have positive feeling towards the school and its staff, they would persist more in their studies than the adolescents who did not like the educational framework that would tend to commit vandalism and anti-social behaviour during their stay in the classroom (Motola, 2010).

\section{Educational dropout in Israel}

In modern Israel, the Ministry of Education has set a core goal to minimize the dropout problem. There are quite a number of youths, especially in the Arab population, who do not make the most of the educational frameworks available to them and they drop out early from the system (Shemesh,2013; Lloyd-Jones et al., 2010; Ben-Rav and KahanStrawczynski, 2011).

Looking at the statistical data, tremendous positive changes were made in the Israelian educational system for reducing educational dropout. Studies show that, 40 years ago, in 1980 the educational dropout rate for the Jewish population was 20,5 percent and for the Arab population 48,7 percent. Twenty years ago (data from 2001) the dropout rate decreased to 4,5 percent among Jewish youngsters and 20,7 percent for Arab youngsters (Cohen-Navot, Ellenbogen-Frankovits \& Reinfeld, 2001). Latest official data show that today the dropout rate (data from 2019) is 2,2 percent for the Jewish youngsters and 3,2 percent for the Arab ones (Central Bureau of Statistics, 2019).

Even if the general data on educational dropout rates shows positive evolutions, studies show significant differences between the different categories of population and some differences on the quality of the educational process between the Hebrew and the Arabic educational systems (Altinok, 2010) that can influence negatively the dropout rates in the future. The most vulnerable categories of population in Israel from this perspective are the ultra-orthodox, the Arabs, especially the Bedouin population and the Ethiopian immigrant community (Arkin \& Cojocaru, 2018).

Today, the covert and overt dropout rate in Israel is approximately $11 \%$. The causes of dropout are many, but several specific causes for Israel's young population were identified. One main factor is the transition from one formal framework to another during transition from middle school to high school (Ben Rav and Kahan-Strawczynski, 2011). 
This situation involves many difficulties like increased subjects of study, the multiplicity of staff members, and the burden of learning difficulties. Besides this, also familial factors (such as divorce, parental unemployment, neglect), personal factors (learning disabilities) and cultural factors (immigration) are also contributing to the educational dropout of Israeli youngsters.

The education system in Israel has been coping with the dropout phenomenon for many years since education became compulsory in Israel and pupils are not allowed to drop out of the educational system. The system had to take immediate methods and actions to deal with the phenomenon.

The main methods of action that have been taken, include the existence of a variety of study tracks, that answer the students' needs and cope with their personal study pace. Another way to cope with dropout is expanding the possibility of taking matriculation exams, where pupils have the ability and the opportunity to finish and graduate school.

The education system is running unique programs which empower the pupil's personality, like horse riding, cooking, thinking skills and extreme sports. Such programs are also aimed at preventing dropouts.

\section{Tendencies of educational dropout rates for youngsters from middle and high school in Israel, in the last ten school years - secondary data analysis:}

\section{Research design:}

As stated before, recent data indicates that the educational dropout rates are continuously decreasing in Israel, showing that the measures undertaken by the national education system are effective from this perspective.

In this part of the article, using secondary data analysis, the aim is to analyse the main tendencies of the educational dropout of Israeli students from middle and high school level attending public schools in the last ten school years.

The source for the data used in the analysis is the Central Bureau of Statistics from Israel. Data released in the Statistical Abstracts of Israel for the last ten year (from 2010 to 2019 were investigated and data was extracted from the tables entitled "Students in Grades 7-12 who Dropped Out of the Educational System of the Ministry of Education", included in the Education section of the statistical abstracts.

Two variables were included in the analysis:

a) The grade in which the educational dropout happened. The Israelian education system has 12 mandatory grades, split into: primary school - grades 1 to 6; middle school - grades 7 to 9; and high school - grades 10 to 12.

b) The type of educational system. In Israel the national education system is divided into two main sub-systems: the Hebrew Education System, addressed to the Hebrew speaking nationals and the Arab Educational System, addressed to the Arabic speaking ones. Both systems operate by the same structure, described within variable one. 


\section{Secondary data analysis:}

Using both variables, from the data extracted resulted Table 1, depicting the educational dropout rates for students from grade 7 to 12, in the last ten school years, separated by the two main educational systems: Hebrew and Arabic. At the end, a ten-year mean was calculated also divided by grades and educational systems.

Table nr. 1. Dropout rates for middle school and high-school students in Israel's educational system

\begin{tabular}{|c|c|c|c|c|c|c|c|c|}
\hline & & & & & & & & \\
\hline & & $\begin{array}{c}\text { Grade } \\
7\end{array}$ & $\begin{array}{c}\text { Grade } \\
\quad 8\end{array}$ & $\begin{array}{c}\text { Grade } \\
\quad 9\end{array}$ & $\begin{array}{c}\text { Grade } \\
10\end{array}$ & $\begin{array}{c}\text { Grade } \\
11\end{array}$ & $\begin{array}{c}\text { Grade } \\
12\end{array}$ & Total \\
\hline \multirow{2}{*}{$\begin{array}{c}2008 / 2009- \\
2009 / 2010\end{array}$} & Hebrew & 1,2 & 5,5 & 5,3 & 3,8 & 6,9 & 2,1 & 4,2 \\
\hline & Arab & 1,8 & 4,6 & 15,7 & 7,0 & 6,4 & 1,3 & 6,2 \\
\hline \multirow{2}{*}{$\begin{array}{c}2009 / 2010- \\
2010 / 2011\end{array}$} & Hebrew & 0,6 & 2,4 & 2,7 & 3,0 & 5,6 & 1,8 & 2,7 \\
\hline & Arab & 1,0 & 4,2 & 10,4 & 5,5 & 5,3 & 1,8 & 4,7 \\
\hline \multirow{2}{*}{$\begin{array}{c}2010 / 2011- \\
2011 / 2012\end{array}$} & Hebrew & 0,6 & 2,0 & 2,6 & 2,8 & 6,2 & 1,5 & 2,6 \\
\hline & Arab & 1,1 & 4,1 & 9,7 & 5,7 & 5,1 & 2,0 & 4,6 \\
\hline \multirow{2}{*}{$\begin{array}{c}2011 / 2012- \\
2012 / 2013\end{array}$} & Hebrew & 1,0 & 2,7 & 2,9 & 2,7 & 6,0 & 1,6 & 2,8 \\
\hline & Arab & 1,3 & 3,8 & 9,8 & 6,0 & 5,2 & 1,8 & 4,7 \\
\hline \multirow{2}{*}{$\begin{array}{c}2012 / 2013- \\
2013 / 2014\end{array}$} & Hebrew & 0,7 & 2,3 & 2,2 & 2,4 & 5,4 & 1,4 & 2,4 \\
\hline & Arab & 1,0 & 3,6 & 8,6 & 5,2 & 4,6 & 1,6 & 4,1 \\
\hline \multirow{2}{*}{$\begin{array}{c}2013 / 2014- \\
2014 / 2015\end{array}$} & Hebrew & 0,6 & 2,0 & 1,9 & 2,1 & 5,0 & 1,1 & 2,1 \\
\hline & Arab & 1,3 & 3,1 & 7,4 & 4,1 & 3,7 & 0,9 & 3,5 \\
\hline \multirow{2}{*}{$\begin{array}{c}2014 / 2015- \\
2015 / 2016\end{array}$} & Hebrew & 0,7 & 2,1 & 2,2 & 2,0 & 5,1 & 1,3 & 2,2 \\
\hline & Arab & 0,8 & 2,9 & 7,2 & 4,3 & 3,9 & 1,0 & 3,4 \\
\hline \multirow{2}{*}{$\begin{array}{c}2015 / 2016- \\
2016 / 2017 \\
\end{array}$} & Hebrew & 0,7 & 2,0 & 2,0 & 2,0 & 5,4 & 1,3 & 2,2 \\
\hline & Arab & 1,3 & 3,3 & 7,5 & 4,0 & 3,7 & 1,1 & 3,5 \\
\hline \multirow{2}{*}{$\begin{array}{c}2016 / 2017- \\
2017 / 2018\end{array}$} & Hebrew & 0,7 & 2,0 & 1,9 & 1,9 & 4,8 & 1,3 & 2,1 \\
\hline & Arab & 1,1 & 3,0 & 7,4 & 4,2 & 3,9 & 1,2 & 3,5 \\
\hline \multirow{2}{*}{$\begin{array}{c}2017 / 2018- \\
2018 / 2019 \\
\end{array}$} & Hebrew & 0,8 & 2,2 & 1,8 & 1,9 & 5,4 & 1,2 & 2,2 \\
\hline & Arab & 0,9 & 3,2 & 6,6 & 3,7 & 3,7 & 1,0 & 3,2 \\
\hline \multirow[t]{2}{*}{ Ten-year mean } & Hebrew & 0,76 & 2,52 & 2,55 & 2,46 & 5,58 & 1,46 & 2,55 \\
\hline & Arab & 1,16 & 3,58 & 9,03 & 4,97 & 4,55 & 1,37 & 4,14 \\
\hline
\end{tabular}

Source: Central Bureau of Statistics - Statistical Abstracts of Israel 2010 to 2019 (no, 61 to 70) - Students in Grades 7-12 who Dropped Out of the Educational System of the Ministry of Education

Analysing the table, the most obvious observation that can be made is the gap between the two education systems in relation with school dropout, the Arab educational system registering considerably higher rates than the Hebrew (a ten year mean of 4,14 percent compared to only 2,55 percent).

First observation that can be made from Figure 1 is that even if there are differences in dropout rate between the two systems, the general tendencies seem to function in mirror. For example, a high reduction of dropout rate can be observed for both educational systems in the first interval (from 6,2 percent to 4,7\% for the Arab educational system and from 4,2 percent to 2,7 percent for the Hebrew educational system.

Figure 1 shows the yearly general dropout rates by educational systems: 


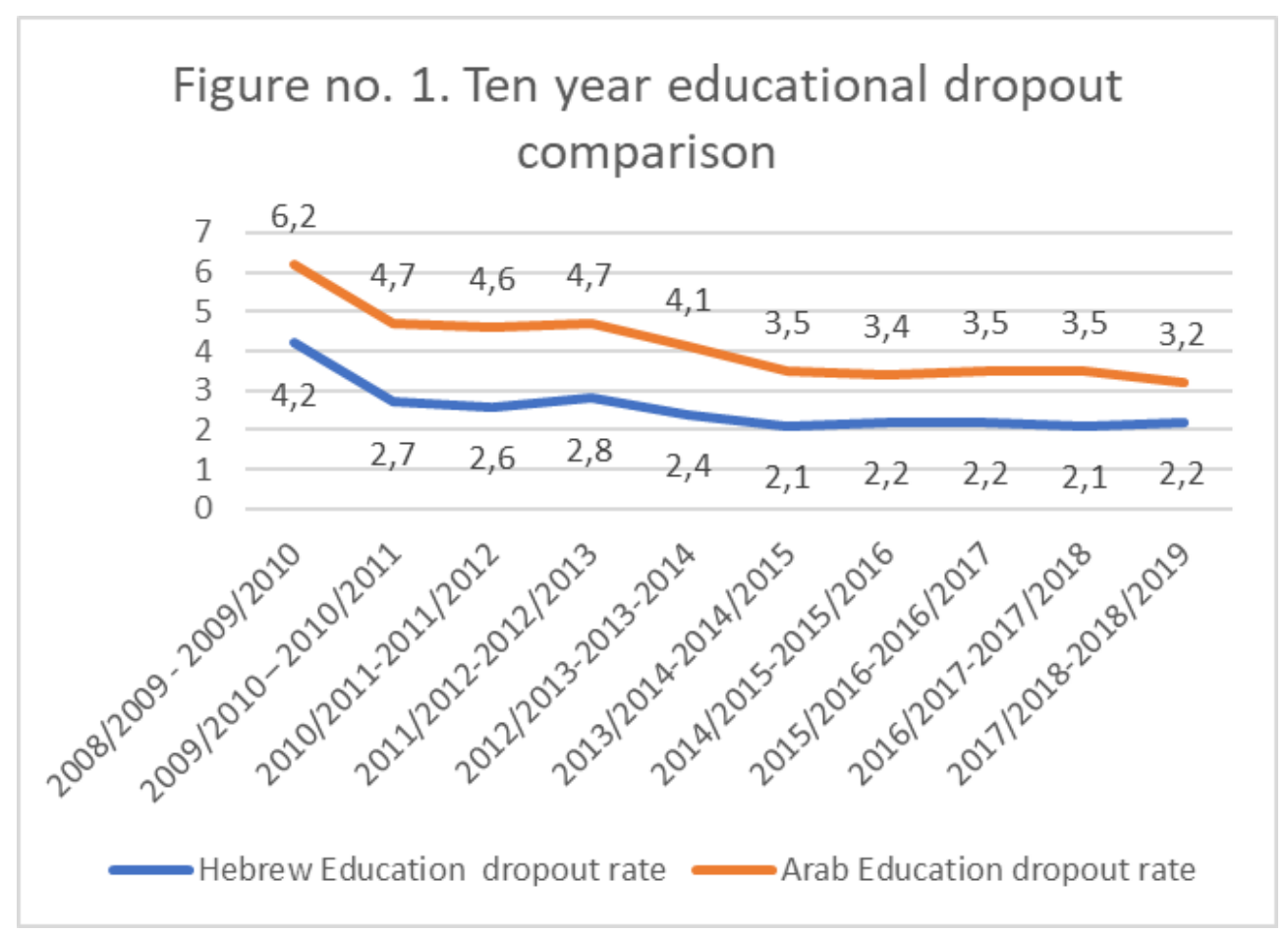

Figure 1. Ten-year educational dropout comparison

Continuing, both systems tend to have slightly increased dropout rates between the school years 2011/2012 and 2012/2013 after that both dropping the rate again considerably and maintaining lower rates continuously for the next school years. And finally, both educational systems register slightly lower rates between the last two school years.

The second observation is that both educational systems registered important decrease in school dropout in the last ten school years, the Hebrew system decreasing from 4,2 percent to 2,2 percent ( 2 percentual points). The Arab system registered even a higher reduction of the dropout rates: 3 percentual points from 6,2 percent to 3,2\%.

And finally the third observation on the data from Figure 1 is that the gap between the two educational systems has been reduced also in the last ten school years, starting from 2 percentual points in the first three intervals and reaching only 1 percentual point difference between the last two school years (3,2\% dropout rate the Arab educational system, compared with 2,2\% dropout rate for the Hebrew educational system).

Continuing with the secondary data analysis, Figure 2 reveals a comparison of the dropout rates between the two educational system by grades. The value considered is the ten-year mean of the dropout rate. 


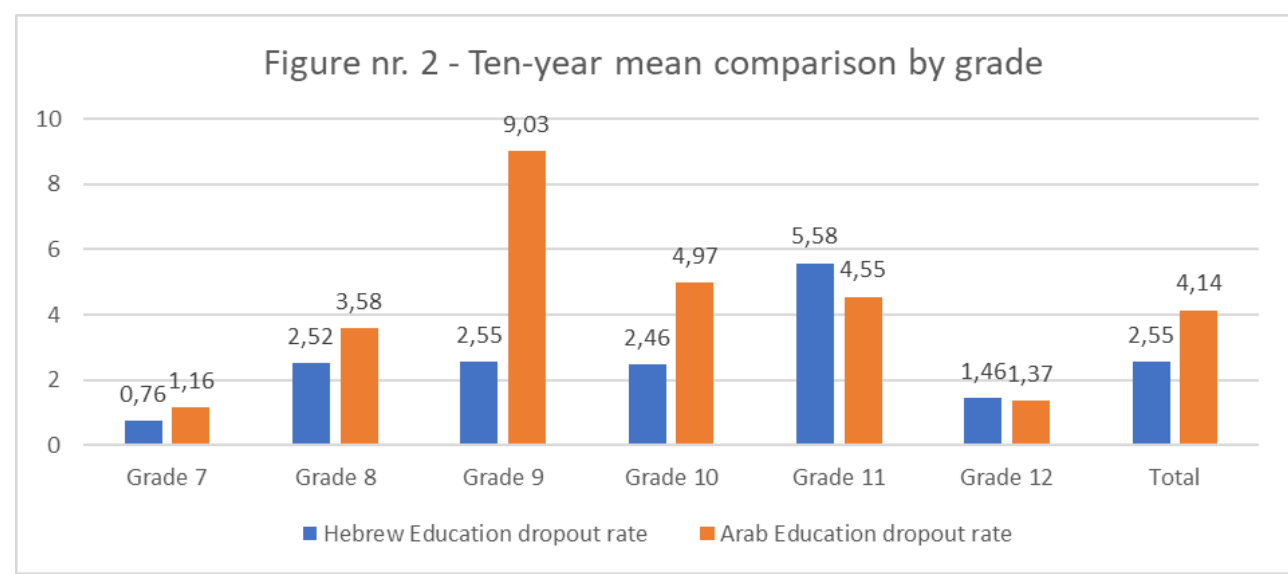

Figure 2. Ten-year mean comparison by grade

In the seventh grade (first grade of middle school) both dropout rates register low levels $(0,76$ percent for the Hebrew education system and 1,16 percent for the Arab education system), slightly higher for the Arab education system (plus 0,4).

In the eighth and the ninth grade the dropout rate for the Hebrew education system is very similar to the general mean $(2,52 / 2,55$ percent compared with $2,55 \%$ general mean). The Arab educational system registers in the eight grade dropout rates below the mean $(3,58$ percent compared with the mean of 4,14 percent $)$, but in the ninth grade the dropout rate is more than twice in comparison with the general mean $(9,03$ percent compared with 4,14 percent). The data reveals in consequence that youngster attending the Arab educational system tend to dropout massively after middle school completion.

Following the high school period, the tendencies are kept in the tenth grade, youngsters attending the Hebrew educational system having similar dropout rates than the general mean (2,46 percent compared with 2,55\%). Also, the dropout rate from the Arab educational system is only slightly higher than the general mean 44,97 percent compared with 4,97 percent).

The eleventh grade show a turn from the general tendencies, the Hebrew educational system registering a dropout rate almost double compared with the general mean (5,58 percent compared to 2,55 percent) and even higher than the dropout rate of the Arab educational system for the same grade (5,58 percent compared to 4,55 percent). The Arab educational system dropout rate at this stage is only slightly higher than its general mean $(4,55$ percent compared with 4,14 percent).

The twelve grade shows low dropout grades for both educational systems. The Hebrew education system registers 1,46 percent dropout rate compared with the 2,55 percent of the general mean. Interesting enough, the Arab education system registers only 1,37 percent dropout rate in the twelve grade, meaning a rate that is three time lower than its general mean $(4,14$ percent $)$ and even lower than the similar one from the Hebrew education system. 


\section{Conclusions}

The importance of reducing the educational dropout rates is clear do to the variety of societal dimensions that it affects. The secondary data analysis and other recent studies show that the phenomenon of dropping out in Israel is effectively handled in the last decade by the responsible authorities as general tendencies of the educational system in this regard. The general dropout rate continuously decreased, both for the Hebrew and Arab education system. Even if the dropout rates for the Arab educational system remain higher, the gap between the two systems decreased also in the last decade.

For the Arab educational system, the dropout rate during and after the ninth grade stands out, revealing a persistent structural barrier for the youngsters attending this system to access high school studies.

Further research needs to be done on recent data that should explore in depth the problematic and expend the analysis on in-risk categories of young population, like the ultra-orthodox, Ethiopian immigrants (Arkin \& Cojocaru, 2018) and the Bedouin population.

\section{References}

Altinok, N. (2010). An Analysis of Schooling Quality Differences in Israel and Palestinian National Authority during the Second Intifada. Background Paper to the Education for All Global Monitoring Report 2011. Andrei, T., Teodorescu, D. \& Oancea, B. (2011). Characteristics and causes of school dropout in the countries of the European Union. In Procedia-Social and Behavioral Sciences, 28, 328-332.

Arkin, N., Cojocaru, S. (2018). Youth Dropouts in Israel and Their Treatment in the Youth Advancement Units, In Revista de cercetare și intervenție socială, 61, 218-230.

Atkinson, M., Halsey, K., Wilkin, A., \& Kinder, K. (2000). Raising Attendance: A Detailed Study of Education Welfare Service Working Practices. National Foundation for educational research (NFER).

Ben-Rav, D., Kahan-Strawczynski, P. (2011). Planning services and interventions for children and youth at the Verge.

Cabus, S. J., \& De Witte, K. (2016). Why do students leave education early? Theory and evidence on high school dropout rates. In Journal of Forecasting, 35(8), 690-702.

Central Bureau of Statistics (2019). Statistical Abstracts of Israel 2010 to 2019 (no, 61 to 70) - Students in Grades 7-12 who Dropped Out of the Educational System of the Ministry of Education, available at https://www.cbs.gov.il/.

Cohen-Navot, M. (2011). School intervention for children and youth at risk. A special report was written as a background document for Ashalim, as part of the formulation of a three-year work plan for the period 2006-2011: Jerusalem: Myers-Joint-Brookdale Institute.

Cohen-Navot, M. Ellenbogen-Frankowitz, S. \& Reinfeld, T. (2012). The overt and covert dropout among youths. Jerusalem: The Knesset and Joint-Brookdale Institute.

Cohen-Navot, M., Ellenbogen-Frankovits, S., Reinfeld, T. (2001). School Dropouts and School Disengagement. Research Report. The Knesset Research and Information Center

Dekkers, H., \& Claassen, A. (2001). Dropouts: Disadvantaged by Definition? A Study of the Perspective of Very Early School Leavers. In Studies in Educational Evaluation, 27(4): 341-54.

Dovrat Committee (2005). National Education Program: Because every child deserves more. Jerusalem, Ministry of Education Available at https://www.makorrishon.co.il/nrg/images/stuff/news/Dovrat_05.01.05.pdf. 
Dupéré, V., Dion, E., Leventhal, T., Archambault, I., Crosnoe, R., \& Janosz, M. (2018). High school dropout in proximal context: The triggering role of stressful life events. In Child development, 89(2): e107-e122.

Dupéré, V., Goulet, M., Archambault, I., Dion, E., Leventhal, T., \& Crosnoe, R. (2019). Circumstances Preceding Dropout Among Rural High School Students: A Comparison with Urban Peers. In Journal of Research in Rural Education, 35(3).

Englund, M. M., Egeland, B., \& Collins, W. A. (2008). Exceptions to high school dropout predictions in a lowincome sample: Do adults make a difference?. In Journal of social issues, 64(1), 77-94.

Ferguson, B., Tilleczek, K., Boydell, K., Rummens, J. A., Cote, D., \& Roth-Edney, D. (2005). Early school leavers: Understanding the lived reality of student disengagement from secondary school. Final Report submitted to the Ontario Ministry of Education

Knesting-Lund, K., O'Rourke, B., \& Gabriele, A. (2015). Teachers' efficacy for supporting at-risk students and their perceived role in dropout prevention. In Journal of Studies in Education, 5(2), 187.

Lahav, H. (2013). Youths at risk - the phenomenon in perspective. In: Shemesh, A. (ed.). From Disconnection to Integration, 10, 17-8. Jerusalem: The Ministry of Education, Society and Youths Administration.

Lloyd-Jones, S., Bowen, R., Holtom, D., Griffin, T., \& Sims, J. (2010). A qualitative research study to explore young people's disengagement from learning.

Moore, P. (2008). The psycho-social educational approach in the service of increasing underachievers and at risk. Joint-Israel Ashalim.

Motola, M. (2010). "Covert and Overt Dropouts in Israel," Echo of Education. In Journal of the Teachers' Union in Israel, vol. 84.

Shemesh, A. (2013). Program for the prevention and promotion of youths at risk at schools, based on a system model supporting learning and education. Project proposal Yaniv, internal document. Tel Aviv: Ministry of Education, Culture and Sport, and Youth Administration and Youth advancement. 